\title{
TGF- $\beta$ induces periodontal ligament stem cell senescence through increase of ROS production
}

\author{
CHUN FAN $^{1}$, QIUXIA JI ${ }^{1}$, CHUNYANG ZHANG $^{1}$, SHUO XU $^{1}$, HUI SUN $^{1}$ and ZHIYUAN LI ${ }^{2}$ \\ ${ }^{1}$ Department of Periodontology; ${ }^{2}$ Key Laboratory, Department of Otolaryngology-Head and Neck Surgery, \\ Affiliated Hospital of Qingdao University, Qingdao, Shandong 266555, P.R. China
}

Received January 11, 2019; Accepted July 25, 2019

DOI: $10.3892 / \mathrm{mmr} .2019 .10580$

\begin{abstract}
Periodontal ligament stem cells (PDLSCs) are vital for the regeneration of periodontal tissue. Transforming growth factor (TGF) $\beta 1$, a potent stimulator of tissue regeneration, is extensive and abundant in the bone matrix. However, the effect of TGF- $\beta 1$ in periodontal differentiation remains to be elucidated. The present study aimed to evaluate the effect of TGF- $\beta 1$ on human PDLSCs. PDLSCs were isolated using CD146 microbeads, and characterized by flow cytometry. The present study demonstrated that treatment with TGF- $\beta 1$ induced PDLSC senescence, characterized by increases in senescence-associated beta-galactosidase activity and elevation of both p16 and p21 expression. Furthermore, TGF- $\beta 1$ treatment demonstrated the capacity to induce the production of reactive oxygen species (ROS). Of note, addition of a ROS scavenger successfully rescued the TGF- $\beta 1$-induced PDLSC senescence. Thus, the present results indicated that TGF- $\beta 1$ may serve a vital role in PDLSC senescence, and thus represent a potential target involved in the fabrication and formation of hard tissue for clinical treatment.
\end{abstract}

\section{Introduction}

Periodontal ligament (PDL) is the connective tissue located between the alveolar bone and tooth root. If PDL is severely damaged by periodontitis, regeneration is difficult (1). Periodontal ligament stem cells (PDLSCs) are essential

Correspondence to: Mr. Zhiyuan Li, Key Laboratory, Department of Otolaryngology-Head and Neck Surgery, Affiliated Hospital of Qingdao University, 1677 Wutaishan Road, Qingdao, Shandong 266555, P.R. China

E-mail: zyli0120@163.com

Ms. Hui Sun, Department of Periodontology, Affiliated Hospital of Qingdao University, 1677 Wutaishan Road, Qingdao, Shandong 266555, P.R. China

E-mail: yuting-456@163.com

Key words: periodontal ligament stem cells, transforming growth factor- $\beta$, cellular senescence, reactive oxygen species for periodontal tissue regeneration, which often forms a cementum/PDL-like structure after transplantation in vivo $(1,2)$. However, the mechanisms responsible for regulating PDLSC differentiation have yet to be fully elucidated. PDL regeneration involves fiber fabrication and hard tissue formation, such as alveolar bone and cementum. It is significative for the stimulation of PDLSCs to differentiate into osteoblast, cementoblast and ligaments in damaged periodontal tissue regeneration. The use of morphogens and growth factors have been shown to stimulate PDLSC differentiation (3-5).

Transforming growth factor (TGF) $\beta 1$ is a potent stimulator of tissue regeneration, and is abundant in the bone matrix $(6,7)$. A previous study found that TGF- $\beta 1$ can improve bone regeneration in animal models of guided tissue regeneration (8). However, a previous study reported that TGF- $\beta 1$ inhibited primary PDL cell cementogenic and osteogenic differentiation via competition with bone morphogenetic protein 2 (9). The differential effects of TGF- $\beta 1$ on fibrogenesis, chondrogenesis and osteogenesis have been identified by comparing in vivo and in vitro experiments, suggesting a controversial role for TGF- $\beta 1$ in periodontal differentiation $(10,11)$.

Cellular senescence results in irreversible cell cycle arrest, as well as a series of morphological and functional changes, which may further inhibit the potential for self-renewal in PDLSCs (12-14). The acquisition of a senescence-associated secretory phenotype (SASP) reinforces senescence and stimulates the immune system to clear the senescent cells (15). Cellular senescence can be induced by various stimuli and stressors, including DNA damage, metabolic insults, oxidative stresses, oncogene activation and epigenetic changes (16-18). A number of studies suggest that TGF- $\beta 1$ is also capable of inducing senescence in tumor and other cells (19-21). However, whether TGF- $\beta 1$ induces PDLSC senescence has yet to be clarified. Thus, the present study attempted to investigate the effect of TGF- $\beta 1$ on the senescence of PDLSCs and its association to reactive oxygen species (ROS) generation, in order to elucidate the function of TGF- $\beta 1$ in periodontal differentiation.

\section{Materials and methods}

Human PDLSC culture and treatment. PDL tissues were collected from healthy third molar teeth extracted from ten male and eight female dental surgery patients aged between 
18 and 25 years old who had visited the Department of Periodontology in the Affiliated Hospital of Qingdao University from February 2018 to April 2019. The study guidelines were approved by the Review Board of the Affiliated Hospital of Qingdao University. Normal periodontal tissues were digested using dispase ( $4 \mathrm{mg} / \mathrm{ml}$; Sigma-Aldrich; Merck KGaA) and collagenase ( $3 \mathrm{mg} / \mathrm{ml}$; Sigma-Aldrich; Merck KGaA) for $1 \mathrm{~h}$ at $37^{\circ} \mathrm{C}$. Cell suspensions were cultured in $\alpha$-MEM (HyClone; GE Healthcare Life Sciences) supplemented with $20 \%$ fetal bovine serum (HyClone; GE Healthcare Life Sciences) and $1 \%$ streptomycin and penicillin at $37^{\circ} \mathrm{C}$ in $5 \% \mathrm{CO}_{2}$. PDLSCs were isolated from third-passage periodontal ligament cells using a cluster of differentiation (CD)146 microbead kit (Miltenyi Biotec $\mathrm{GmbH}$ ) according to the manufacturer's instructions. For characterization of the isolated cells, the PDLSCs were pre-incubated with Human TruStain FcX ${ }^{\mathrm{TM}}$ (Fc Receptor Blocking Solution; cat. no. 422301; BioLegend, Inc.) for $10 \mathrm{~min}$ at room temperature, and then stained with the following antibodies for $30 \mathrm{~min}$ at $4^{\circ} \mathrm{C}$ : Anti-human PE-conjugated CD34 (cat. no. 12-0349-42), CD44 (cat. no. 12-0441-82), CD45 (cat. no. 12-9459-42), CD90 (cat. no. 12-0909-42) and CD105 (cat. no. 12-1057-42) antibodies (eBioscience; Thermo Fisher Scientific, Inc.). Flow cytometry analysis was performed on a FACS Calibur flow cytometer (BD Biosciences) and analyzed using WinMDI version 2.9 software (http://www.cyto.purdue. edu/flowcyt/software/Winmdi.htm).

For cell treatments, the isolated PDLSCs were starved in serum-free $\alpha$-MEM overnight and then cultured in fresh serum-free $\alpha$-MEM supplemented with TGF- $\beta 1$ (10 ng/ml; PeproTech, Inc., ) alone, or in combination with $\mathrm{N}$-acetyl-L-cysteine (NAC; $10 \mathrm{mM}$; Beyotime Institute of Biotechnology) or LY364947 ( $2 \mu \mathrm{M}$; Selleck Chemicals).

Reverse transcription-quantitative PCR (RT-qPCR). Total RNA was extracted from cultured PDLSCs with TRIzol reagent (Invitrogen; Thermo Fisher Scientific, Inc.) and then reverse-transcribed to cDNA using a PrimeScript RT reagent kit (Takara Bio, Inc.) according to the manufacturer's protocols. qPCR analysis was performed on a Light Cycler 96 (Roche Diagnostics GmbH) using SYBR Green mix (Takara Bio, Inc.). Samples were initially denatured for $30 \mathrm{sec}$ at $95^{\circ} \mathrm{C}$, followed by 40 cycles of denaturation for $5 \mathrm{sec}$ at $95^{\circ} \mathrm{C}$ and annealing for $30 \mathrm{sec}$ at $60^{\circ} \mathrm{C}$. Primers used for qPCR are listed in Table I. The $2^{-\triangle \Delta C q}$ method normalized to GAPDH was used for quantification (22). Experiments were repeated three times independently.

ROS measurement. ROS were detected using a MitoSOX Red Superoxide Indicator (Invitrogen; Thermo Fisher Scientific, Inc.), or hydrogen peroxide-specific peroxy orange 1 (PO1; APExBIO Technology LLC) probe. Following treatment with TGF- $\beta 1$, PDLSCs were incubated with $5 \mu \mathrm{M}$ MitoSOX Red for $10 \mathrm{~min}$, or $5 \mu \mathrm{M} \mathrm{PO} 1$ for $30 \mathrm{~min}$ at $37^{\circ} \mathrm{C}$. Fluorescence was detected by a FACSCalibur flow cytometer (BD Biosciences) and analyzed using WinMDI version 2.9 software.

Western blot analysis. PDLSCs treated with TGF- $\beta 1$ were lysed in 2\% SDS lysis buffer (Beyotime Institute of Biotechnology). The concentration of protein lysates were assayed using a Pierce $^{\mathrm{TM}}$ BCA protein assay kit (cat. no. 23225; Thermo Fisher Scientific, Inc.). A total of $20 \mu \mathrm{g}$ of protein was resolved via
Table I. Primers used for reverse transcription-quantitative PCR.

\begin{tabular}{lll}
\hline Gene & Primer & \multicolumn{1}{c}{ Sequence $\left(5^{\prime}-3^{\prime}\right)$} \\
\hline GAPDH & $\begin{array}{l}\text { Forward AGGGCTGCTTTAACTCTGGT } \\
\text { Reverse }\end{array}$ & CCCCACTTGATTTTGGAGGGA \\
IL-6 & $\begin{array}{l}\text { Forward GATGAGTACAAAAGTCCTGATCCA } \\
\text { Reverse CTGCAGCCACTGGTTCTGT }\end{array}$ \\
IL-8 & $\begin{array}{l}\text { Forward TTGGCAGCCTTCCTGATTTC } \\
\text { IL-18 }\end{array}$ & $\begin{array}{l}\text { Feverse TGGTCCACTCTCAATCACTCTCA } \\
\text { P21 CACCCCGGACCATATTTATTATAAGT }\end{array}$ \\
Reverse TGTTATCAGGAGGATTCATTCCTT \\
P16 & $\begin{array}{l}\text { Forward GCCTGGACTGTTTCTCTCG } \\
\text { Forward CACGGGTCGGGTGAGAGT }\end{array}$ \\
& Reverse CCCAACGCACCGAATAGTTAC \\
\hline
\end{tabular}

IL, interleukin.

12\% SDS-PAGE and transferred to $0.45-\mu \mathrm{m}$ PVDF membranes. Following $1 \mathrm{~h}$ of blocking with 5\% skimmed milk at room temperature, PVDF membranes were incubated with the following primary antibodies: Anti- $\alpha$-tubulin (1:5,000; cat. no. 11224-1; ProteinTech Group, Inc.); anti-p21 (1:1,000; cat. no. ab109520; Abcam); anti-p16 (1:1,000; cat. no. ab108349; Abcam); and anti-superoxide dismutase2 (SOD2; 1:1,000; cat. no. ab13533; Abcam), and then reacted with horseradish peroxidase (HRP)-conjugated secondary antibodies (1:5,000; cat. no. 31460; Invitrogen; Thermo Fisher Scientific, Inc.). $\alpha$-tubulin was used as internal reference. Signals were visualized using an enhanced chemiluminescent HRP substrate (cat. no. WBKLS0050; EMD Millipore) and ImageJ (version 1.50i; National Institutes of Health) was used for densitometry.

ELISA. An ELISA kit (cat. no. KHC0081; Invitrogen; Thermo Fisher Scientific, Inc.) was used to detect levels of interleukin (IL)- 8 in the cell culture supernatants, according to the manufacturer's instructions.

Senescence-associated beta-galactosidase (SA- $\beta$-Gal) staining. The PDLSCs were treated with TGF- $\beta 1$ alone or combined with NAC or LY364947 for 48 h. SA- $\beta$-gal activity was detected with the SA- $\beta$-gal staining kit (cat. no. RG0039; Beyotime Institute of Biotechnology), in accordance with the manufacturer's protocols.

Statistical analysis. Data are shown as mean \pm standard deviation. One-way analysis of variance (ANOVA) followed by Tukey's post-hoc test was used for comparisons between $>2$ groups. $\mathrm{P}<0.05$ was considered to indicate a statistically significant difference.

\section{Results}

Isolation and characterization of PDLSCs. PDLSCs were isolated using CD146 microbeads. The majority of PDLSCs 


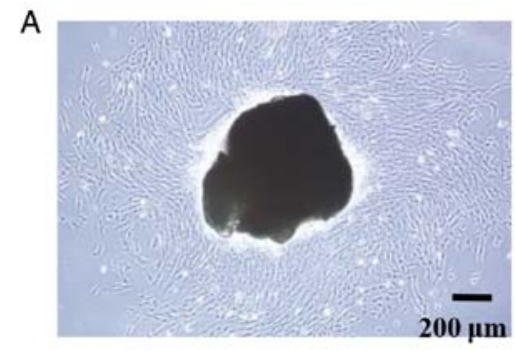

B

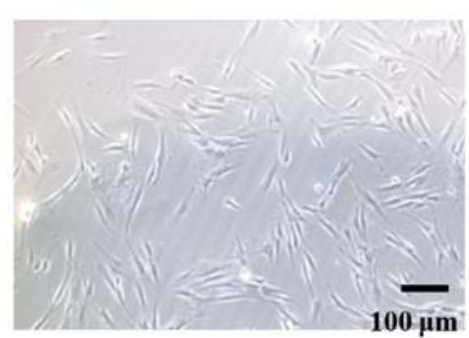

C
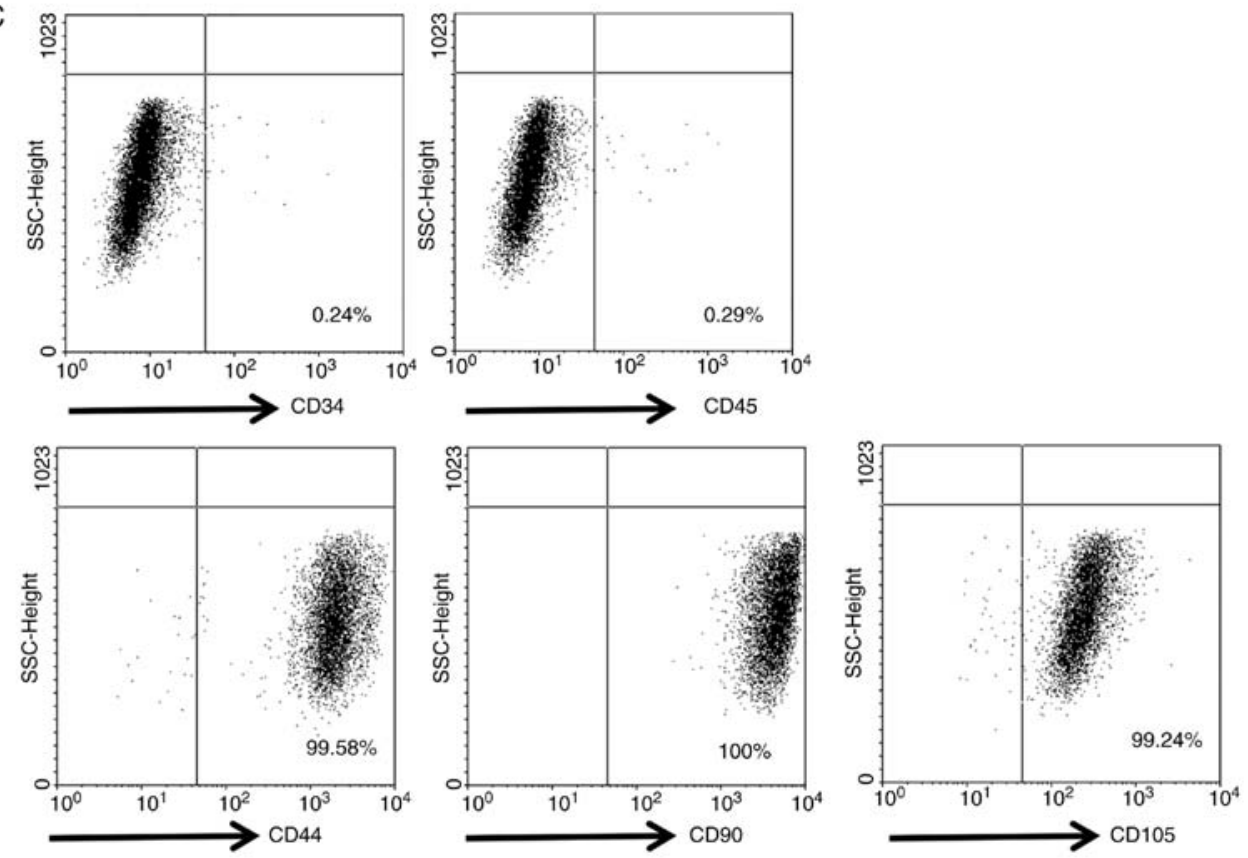

Figure 1. Characterization of PDLSCs. (A) PDL cell clusters exhibited radiating or whirlpool-like morphology. The central structure in this image is a fragment of PDL tissue. Scale bar, $200 \mu \mathrm{m}$ (B) CD146 ${ }^{+}$PDLSCs were small, round, fusiform and triangular. Scale bar, $100 \mu \mathrm{m}$. (C) PDLSCs were positive for the stem cell markers CD44, CD90 and CD105, but negative for CD34 and CD45, as detected by flow cytometry. PDL, periodontal ligament; PDLSCs, PDL stem cells.

exhibited a fibroblastic spindle morphology, and a small round or triangular shape (Fig. 1A and B). The mesenchymal stem cell (MSC) properties of PDLSCs were then characterized, by detecting their expression levels for MSC-specific cell surface antigens by flow cytometry. As presented in Fig. 1C, PDLSCs highly expressed the MSC-specific markers CD44, CD90 and CD105. In addition, the cells were negative for the hematopoietic stem cell marker CD34 and the pan-leukocyte marker CD45.

TGF- $\beta 1$ induces PDLSC senescence. $\beta$-Galactosidase activity is a specific marker for cellular senescence, and is observed only in senescent cells (23). As shown in Fig. 2, following treatment with TGF- $\beta 1$, the percentage of positive PDLSCs for SA- $\beta$-gal staining was significantly increased. TGF- $\beta 1$ treatment also significantly increased the mRNA and protein expression levels of p16 and p21 (Fig. 3). To confirm the effect of TGF- $\beta 1$ on PDLSC senescence, the TGF- $\beta$ signaling pathway was blocked with a specific TGF $\beta$ R inhibitor, LY364947. It was identified that the percentage of SA- $\beta$-gal positive cells decreased significantly (Fig. 2), and the expression levels of p21 and p16 were also downregulated (Fig. S1), following treatment with LY364947. These results indicated that TGF- $\beta 1$ treatment induced PDLSC senescence.
It has been reported that senescent cells release a series of inflammatory cytokines, a process that further reinforces cellular senescence (15). To investigate whether senescent PDLSCs develop a complex SASP, the expression of several key inflammatory mediators was investigated in the present study. Elevated IL-18 and IL-8 mRNA levels (Fig. 4A) and secreted IL-8 protein levels (Fig. 4B) were observed in TGF- $\beta 1$-induced senescent PDLSCs; by contrast, IL- 6 mRNA expression levels were unchanged (Fig. 4A).

TGF- $\beta 1$ treatment increases ROS production in PDLSCs. ROS was detected using the MitoSox Red probe, and the results demonstrated that treatment with TGF- $\beta 1$ for $48 \mathrm{~h}$ markedly increased ROS production in PDLSCs (Fig. 5A and B). $\mathrm{H}_{2} \mathrm{O}_{2}$ was also detected with a PO1 probe. Detection of PO1 further confirmed the TGF- $\beta 1$-induced ROS production (Fig. 5A and B). Additionally, the protein expression levels of SOD2, which is a mitochondrial matrix enzyme and protects mitochondria against ROS insult (24), were obviously downregulated following TGF- $\beta 1$ treatment (Fig. 5C), suggesting the involvement of SOD2 expression levels in cellular senescence.

Senescence of PDLSCs is rescued by NAC. To evaluate the role of ROS in TGF- $\beta 1$-induced PDLSC senescence, 

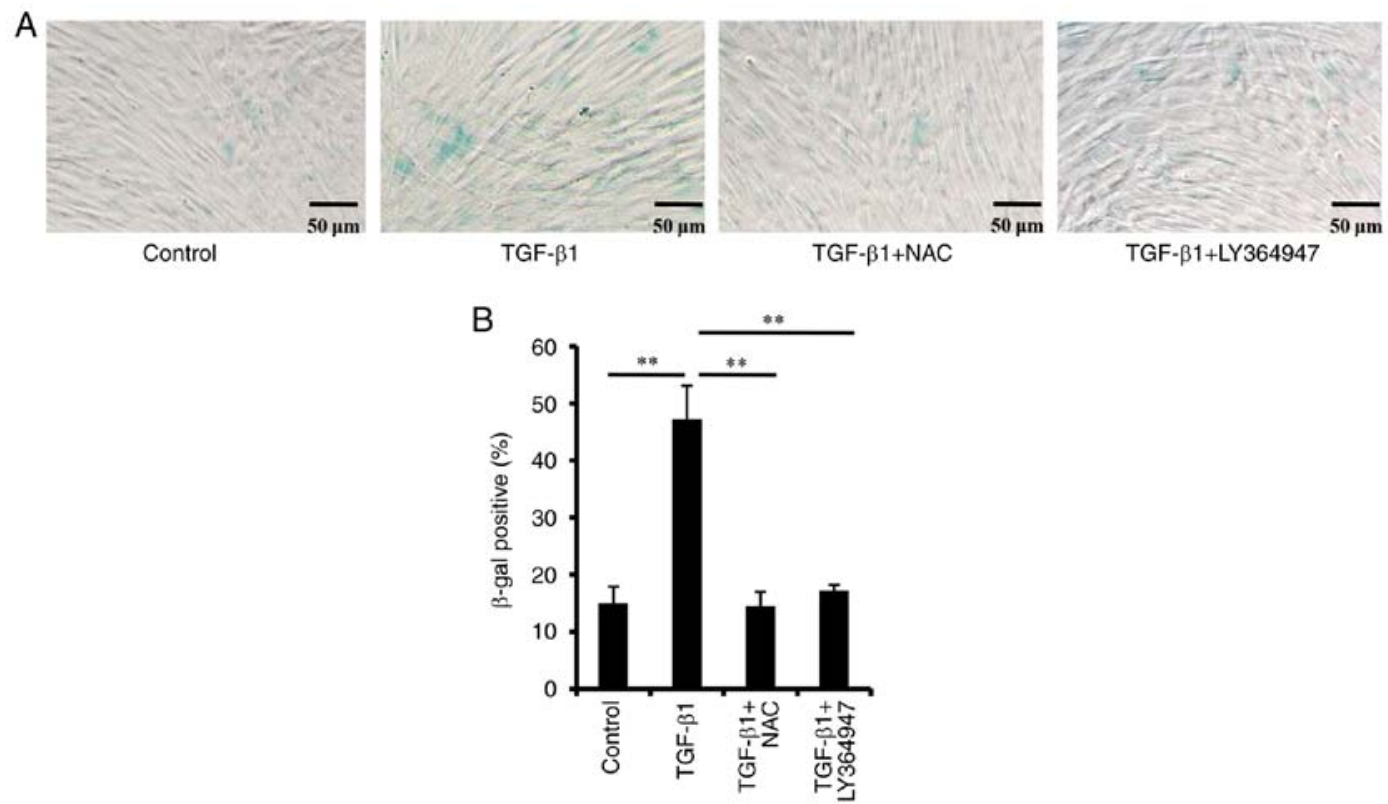

Figure 2. $\beta$-galactosidase activity in PDLSCs after TGF- $\beta 1$ treatment. PDLSCs were treated with $10 \mathrm{ng} / \mathrm{ml}$ TGF- $\beta 1$ alone, or in combination with $10 \mathrm{mM}$ NAC or $2 \mu \mathrm{M}$ LY364947, for $48 \mathrm{~h}$. Senescence was assayed by SA- $\beta$-gal staining. (A) Representative images. Scale bar, $50 \mu \mathrm{m}$. (B) The percentage of SA- $\beta$-gal-positive cells in PDLSCs in each treatment group. Results are presented as mean \pm standard deviation. ** $\mathrm{P}<0.01$, with comparisons indicated by lines. Data are representative of three independent experiments. PDLSCs, periodontal ligament stem cells; TGF- $\beta 1$, transforming growth factor- $\beta 1$; NAC, $\mathrm{N}$-acetyl-L-cysteine; SA- $\beta$-Gal, senescence-associated beta-galactosidase.

A

p21

p16
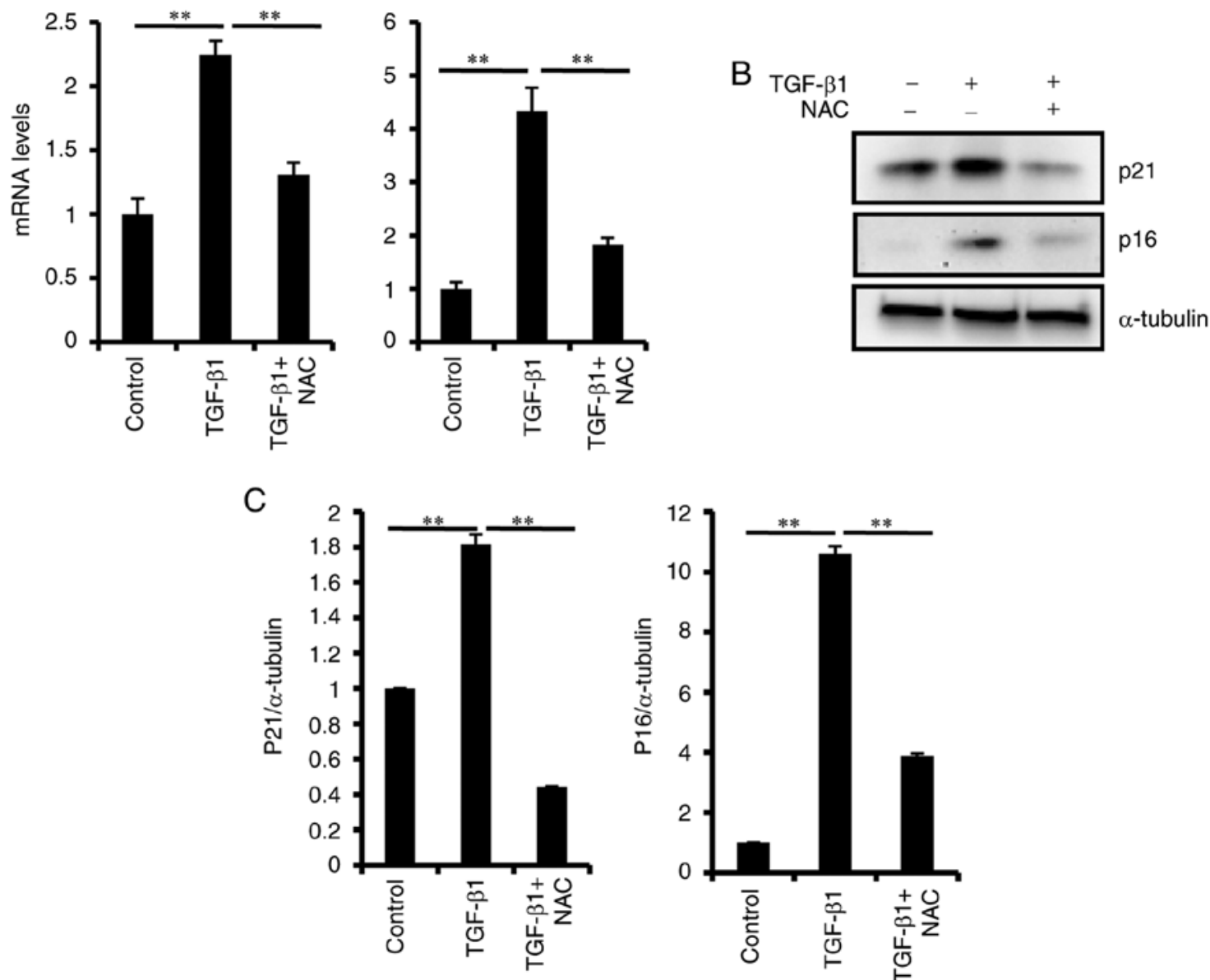

Figure 3. Expression of p16 and p21 in PDLSCs after TGF- $\beta 1$ treatment. (A) mRNA and (B and C) protein expression levels of p16 and p21 in PDLSCs treated with TGF- $\beta 1(10 \mathrm{ng} / \mathrm{ml})$ alone, or in combination with $10 \mathrm{mM} \mathrm{NAC}$, for $48 \mathrm{~h}$. Results are presented as mean \pm standard deviation. ${ }^{* *} \mathrm{P}<0.01$, with comparisons indicated by lines. Data are representative of three independent experiments. PDLSCs, periodontal ligament stem cells; TGF- $\beta 1$, transforming growth factor- $\beta 1$; NAC, N-acetyl-L-cysteine. 
A

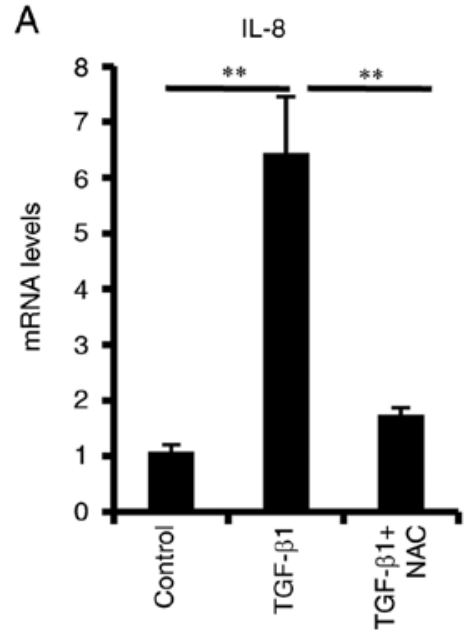

IL-18

B

IL-8
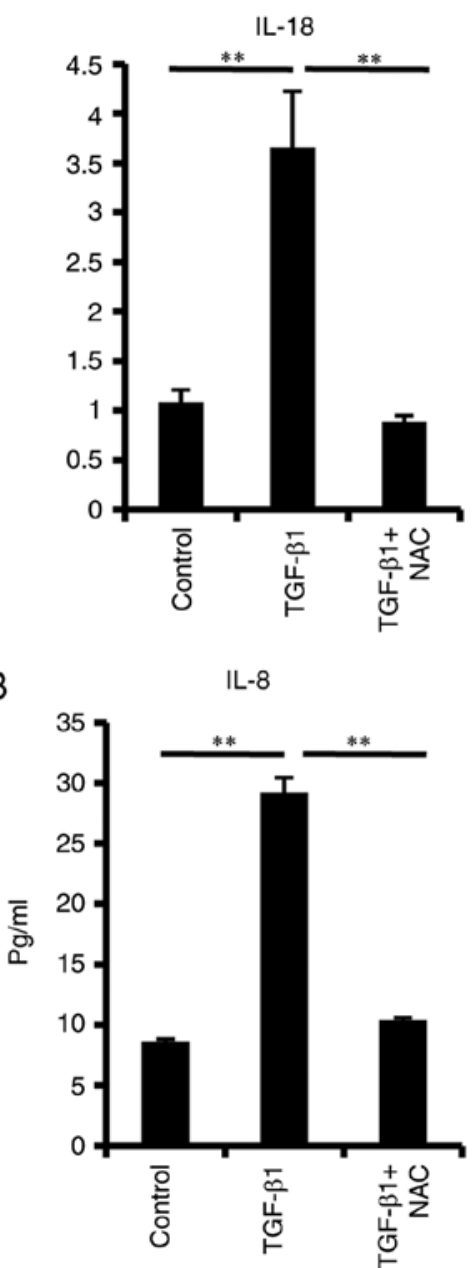

IL-6

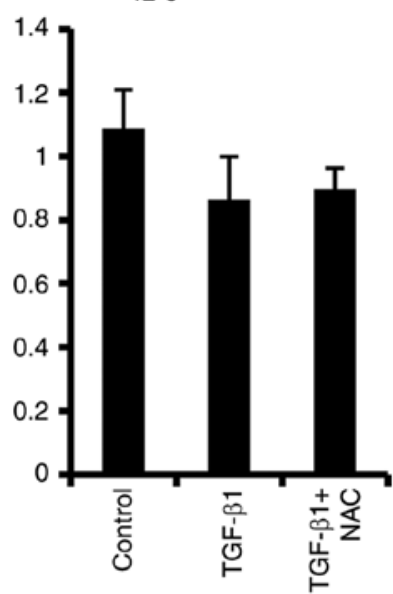

Figure 4. Effects of TGF- $\beta 1$ on cytokine production. (A) mRNA levels of the indicated genes in PDLSCs treated with TGF- $\beta 1$ (10 ng/ml) alone, or in combination with $10 \mathrm{mM}$ NAC, for $72 \mathrm{~h}$. (B) The levels of secreted IL-8 in cultured PDLSC supernatants were detected by ELISA. Results are presented as mean \pm standard deviation. ${ }^{* *} \mathrm{P}<0.01$, with comparisons indicated by lines. Data are representative of three independent experiments. TGF- $\beta 1$, transforming growth factor- $\beta 1$; IL, interleukin.

the physiological mitochondrial ROS scavenger NAC was used in the senescence assay. The results demonstrated that NAC effectively impaired TGF- $\beta 1$-induced ROS production in PDLSCs (Fig. 5A and B). NAC treatment significantly suppressed TGF- $\beta 1$-induced SA- $\beta$-Gal activity (Fig. 2), p16 and p21 expression (Fig. 3), as well as IL-8 and IL-18 production (Fig. 4). These results indicated that ROS were an important mediator of the TGF- $\beta 1$-induced PDLSC senescence.

\section{Discussion}

PDLSCs which are positive for CD146 or STRO-1 have greater osteogenic potential and colony-forming ability than CD146 or STRO-1-negative PDLSCs $(25,26)$. The present study investigated the effect of TGF- $\beta 1$ on CD146 ${ }^{+}$PDLSC senescence. PDLSCs also possess characteristics of MSCs, such as cell surface MSC-specific marker expression $\left(\mathrm{CD} 44^{+}, \mathrm{CD} 73^{+}\right.$, $\mathrm{CD}^{+}, \mathrm{CD}^{\circ} 5^{+}, \mathrm{CD}^{\circ} 5^{-}, \mathrm{CD}^{-} 1^{-}$and $\left.\mathrm{CD} 34^{-}\right)(27,28)$. In accordance with that, the present study characterized the isolated PDLSCs by flow cytometry, and found that the isolated PDLSCs successfully expressed the MSC-specific markers CD44, CD90 and CD105, and were negative for CD34 and the pan-leukocyte marker CD45. The data from the present study demonstrated that TGF- $\beta 1$ increased SA- $\beta$-Gal activity and ROS production in PDLSCs. The expression levels of the aging-related p16 and p21 proteins were also significantly increased following TGF- $\beta 1$ treatment. In addition, expression of the mitochondrial matrix enzyme SOD2 was decreased in TGF- $\beta 1$-treated PDLSCs. Addition of the ROS scavenger NAC repressed the ROS production and PDLSC senescence induced by TGF- $\beta 1$. The data from the present study thus demonstrated that TGF- $\beta 1$ induced PDLSC senescence through the increase of ROS production.

Periodontal disease (PD) is characterized by inflammation and tissue destruction in the periodontal apparatus. PDLSCs are critical to the PDL tissue reconstruction process and are known to differentiate into osteoblastic or cementoblastic cells to form calcified tissue $(29,30)$. Previous studies have indicated that TGF- $\beta 1$ could cause tumor cell senescence $(19,20)$. The present study demonstrated that TGF- $\beta 1$ significantly increased SA- $\beta$-Gal activity in PDLSCs, suggesting that PDLSCs were undergoing senescence. Cellular senescence can result in phenotype changes and low proliferation of PDLSCs (12-14), which may further attenuate the efficiency of PDLSC-based transplantation. PDLSC expression of aging regulators p16 

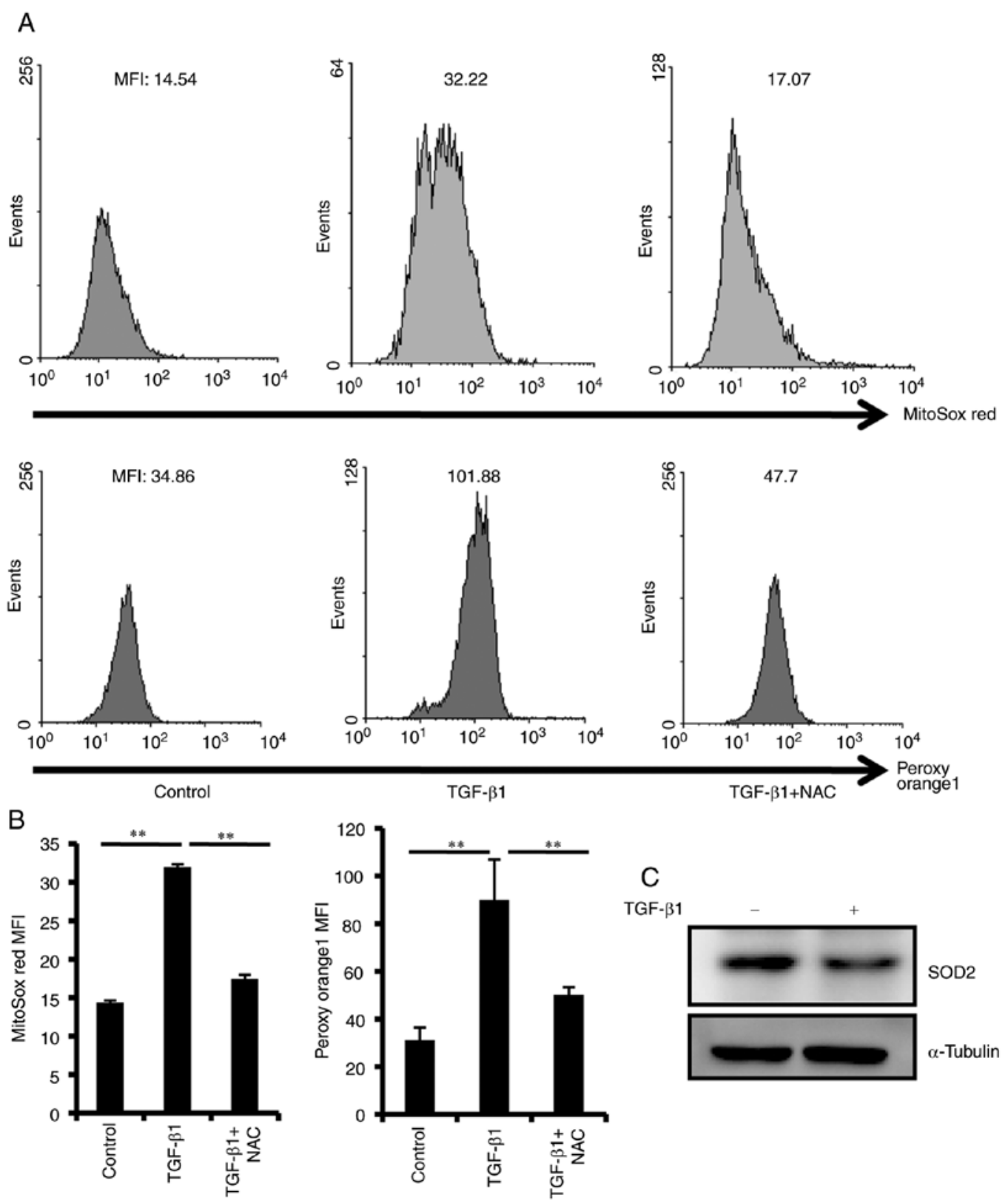

Figure 5. ROS production in PDLSCs after TGF- $\beta 1$ treatment. (A) PDLSCs were treated with $10 \mathrm{ng} / \mathrm{ml}$ TGF- $\beta 1$ alone, or in combination with $10 \mathrm{mM}$ NAC, for $48 \mathrm{~h}$. ROS production was assayed by MitoSOX Red or peroxy orange 1 staining and flow cytometry analysis. Representative plots are shown. (B) Quantification of results from panel A. (C) Protein expression levels of SOD2 in TGF- $\beta 1$-treated PDLSCs. ** P<0.01, with comparisons indicated by lines. Data are representative of three independent experiments. ROS, reactive oxygen species; PDLSCs, periodontal ligament stem cells; TGF- $\beta 1$, transforming growth factor- $\beta 1$; SOD2, superoxide dismutase2; MFI, mean fluorescence intensity.

and p21 was also upregulated significantly following TGF- $\beta 1$ treatment.

Senescent cells usually produce a series of cytokines, chemokines, and other soluble factors, a phenotype called SASP, which is believed to reinforce senescence $(13,15)$. In the present study, elevated IL- 8 and IL-18 expression was detected following TGF- $\beta 1$ treatment, suggesting that TGF- $\beta 1$ was capable of instigating inflammation in PDLSCs. IL- 8 can cause extensive infiltration of neutrophils, which serve an essential role in the inflammatory process (31). Additionally, the levels of IL-8 in periapical lesions has been reported to correlate with pain in patients with apical periodontitis (32). In a recent study, IL-18 was demonstrated to promote matrix metallopeptidase secretion by activating the $\mathrm{NF}-\kappa \mathrm{B}$ signaling pathway in human periodontal ligament fibroblasts, indicating that IL-18 is involved in chronic periodontitis development (33).

The findings of the present study reveal a new role for TGF- $\beta 1$ signaling in PDLSC senescence and SASP production. It should also be noted that TGF- $\beta 1$ serves important roles in cell growth, differentiation and transformation (34). In addition, the complete deletion of TGF- $\beta 1$ is developmentally lethal (34). Concerning the periodontal regeneration, TGF- $\beta 1$ signaling deficiency affects cementoblast differentiation and periodontal wound-healing, indicating that a normal level of TGF- $\beta 1$ is biologically required and thereby protective of the periodontium $(35,36)$. Therefore, appropriate TGF- $\beta 1$ suppression can present a therapeutic basis for treating periodontitis. Cellular senescence was initially considered 
a fail-safe mechanism for tumor suppression (37). However, several studies have shown that senescent cells promote the growth of premalignant or malignant cells, at least partly via SASP $(38,39)$. A specific SASP component, IL-6 also serves an established role in liver regeneration and repair (40). In addition, during periodontal regeneration and wound repair, a phase of inflammation and granulation is indispensable (41), thus making TGF- $\beta 1$-induced SASP a likely contributor to the process of regeneration.

Our previous study found that TGF- $\beta 1$ treatment enhanced ROS production in corneal endothelium cells and further induced cellular senescence (42), which raised the hypothesis that ROS could be involved in PDLSC senescence. The results of the present study demonstrated that ROS production was significantly upregulated in TGF- $\beta 1$-treated PDLSCs. The results also demonstrated that the expression levels of SOD2, which can protect mitochondria against ROS insult (24), were significantly decreased in PDLSCs following TGF- $\beta 1$ treatment. To further examine the role of ROS in TGF- $\beta 1$ induced PDLSC senescence, PDLSCs were treated with the ROS scavenger NAC in combination with TGF- $\beta 1$. The results revealed that NAC significantly inhibited the TGF- $\beta 1$ induced ROS production and SA- $\beta$-Gal activity, suggesting that TGF- $\beta 1$-induced PDLSCs senescence depended on ROS production.

In conclusion, the present study demonstrated that TGF- $\beta 1$, a potent stimulator for tissue regeneration, promoted PDLSC senescence and this effect was dependent on ROS induction.

\section{Acknowledgements}

Not applicable.

\section{Funding}

This work was supported by the National Natural Science Foundation of China (grant no. 81701381).

\section{Availability of data and materials}

The datasets used and/or analyzed during the present study are available from the corresponding author on reasonable request.

\section{Authors' contributions}

CF, HS and ZL designed the study and analyzed the data. $\mathrm{CF}, \mathrm{QJ}$, and $\mathrm{CZ}$ performed cell culture, SA- $\beta$-Gal staining, RT-qPCR and western blotting. CF and SX performed the flow cytometry analysis. CF, HS and ZL wrote the manuscript. All authors read and approved the final manuscript.

\section{Ethics approval and consent to participate}

The present study was approved by the Review Board of the Affiliated Hospital of Qingdao University. Written informed consent was obtained from patients prior to procedure.

\section{Patient consent for publication}

Not applicable.

\section{Competing interests}

The authors declare that they have no competing interests.

\section{References}

1. Liu Y, Zheng Y, Ding G, Fang D, Zhang C, Bartold PM, Gronthos S, Shi S and Wang S: Periodontal ligament stem cell-mediated treatment for periodontitis in miniature swine. Stem Cells 26: 1065-1073, 2008.

2. Huang GT, Gronthos S and Shi S: Mesenchymal stem cells derived from dental tissues vs. those from other sources: Their biology and role in regenerative medicine. J Dent Res 88: 792-806, 2009.

3. Lekic P and McCulloch CA: Periodontal ligament cell population: The central role of fibroblasts in creating a unique tissue. Anat Rec 245: 327-341, 1996.

4. Kao RT, Murakami S and Beirne OR: The use of biologic mediators and tissue engineering in dentistry. Periodontol 2000 50: 127-153, 2009.

5. Li X, Yang H, Zhang Z, Yan Z, Lv H, Zhang Y and Wu B: Concentrated growth factor exudate enhances the proliferation of human periodontal ligament cells in the presence of TNF- $\alpha$. Mol Med Rep 19: 943-950, 2019.

6. Hyun SY, Lee JH, Kang KJ and Jang YJ: Effect of FGF-2, TGF- $\beta-1$, and BMPs on Teno/Ligamentogenesis and Osteo/Cementogenesis of human periodontal ligament stem cells. Mol Cells 40: 550-557, 2017.

7. Shi Y and Massague J: Mechanisms of TGF-beta signaling from cell membrane to the nucleus. Cell 113: 685-700, 2003.

8. Wikesjo UM, Razi SS, Sigurdsson TJ, Tatakis DN, Lee MB, Ongpipattanakul B, Nguyen T and Hardwick R: Periodontal repair in dogs: Effect of recombinant human transforming growth factor-beta1 on guided tissue regeneration. J Clin Periodontol 25: 475-481, 1998.

9. Kawahara T, Yamashita M, Ikegami K, Nakamura T, Yanagita M, Yamada S, Kitamura M and Murakami S: TGF-beta negatively regulates the BMP2-dependent early commitment of periodontal ligament cells into hard tissue forming cells. PLoS One 10: e0125590, 2015.

10. De Gorter DJ, van Dinther M, Korchynskyi O and ten Dijke P: Biphasic effects of transforming growth factor $\beta$ on bone morphogenetic protein-induced osteoblast differentiation. J Bone Miner Res 26: 1178-1187, 2011.

11. Lorda-Diez CI, Montero JA, Martinez-Cue C, Garcia-Porrero JA and Hurle JM: Transforming growth factors beta coordinate cartilage and tendon differentiation in the developing limb mesenchyme. J Biol Chem 284: 29988-29996, 2009.

12. Baker DJ, Wijshake T, Tchkonia T, LeBrasseur NK, Childs BG, van de Sluis B, Kirkland JL and van Deursen JM: Clearance of p16Ink4a-positive senescent cells delays ageing-associated disorders. Nature 479: 232-236, 2011.

13. Lopez-Otin C, Blasco MA, Partridge L, Serrano M and Kroemer G: The hallmarks of aging. Cell 153: 1194-1217, 2013.

14. Burova E, Borodkina A, Shatrova A and Nikolsky N: Sublethal oxidative stress induces the premature senescence of human mesenchymal stem cells derived from endometrium. Oxid Med Cell Longev 2013: 474931, 2013.

15. Acosta JC, Banito A, Wuestefeld T, Georgilis A, Janich P, Morton JP, Athineos D, Kang TW, Lasitschka F, Andrulis M, et al: A complex secretory program orchestrated by the inflammasome controls paracrine senescence. Nat Cell Biol 15: 978-990, 2013.

16. Burton DG and Faragher RG: Cellular senescence: From growth arrest to immunogenic conversion. Age 37: 27, 2015

17. Xu M, Tchkonia T, Ding H, Ogrodnik M, Lubbers ER, Pirtskhalava T, White TA, Johnson KO, Stout MB, Mezera V, et al: JAK inhibition alleviates the cellular senescence-associated secretory phenotype and frailty in old age. Proc Natl Acad Sci USA 112: 6301-6310, 2015.

18. Zou J, Lei T, Guo P, Yu J, Xu Q, Luo Y, Ke R and Huang D: Mechanisms shaping the role of ERK1/2 in cellular senescence (Review). Mol Med Rep 19: 759-770, 2019.

19. Senturk S, Mumcuoglu M, Gursoy-Yuzugullu O, Cingoz B, Akcali KC and Ozturk M: Transforming growth factor-beta induces senescence in hepatocellular carcinoma cells and inhibits tumor growth. Hepatology 52: 966-974, 2010. 
20. Hubackova S, Krejcikova K, Bartek J and Hodny Z: IL1- and TGF $\beta$-Nox 4 signaling, oxidative stress and DNA damage response are shared features of replicative, oncogene-induced, and drug-induced paracrine 'bystander senescence'. Aging 4: 932-951, 2012.

21. Li ZY, Chen ZL, Zhang T, Wei C and Shi WY: TGF- $\beta$ and NF- $\kappa B$ signaling pathway crosstalk potentiates corneal epithelial senescence through an RNA stress response. Aging (Albany NY) 8: 2337-2354, 2016.

22. Livak KJ and Schmittgen TD: Analysis of relative gene expression data using real-time quantitative PCR and the 2(-Delta Delta C(T)) method. Methods 25: 402-408, 2001.

23. Debacq-Chainiaux F, Erusalimsky JD, Campisi J and Toussaint O Protocols to detect senescence-associated beta-galactosidase (SA-betagal) activity, a biomarker of senescent cells in culture and in vivo. Nat Protoc 4: 1798-1806, 2009.

24. Velarde MC, Flynn JM, Day NU, Melov S and Campisi J: Mitochondrial oxidative stress caused by Sod2 deficiency promotes cellular senescence and aging phenotypes in the skin. Aging (Albany NY) 4: 3-12, 2012.

25. Seo BM, Miura M, Gronthos S, Bartold PM, Batouli S, Brahim J, Young M, Robey PG, Wang CY and Shi S: Investigation of multipotent postnatal stem cells from human periodontal ligament. Lancet 364: 149-155, 2004.

26. Wang P, Wang Y, Tang W, Wang X, Pang Y, Yang S, Wei Y, Gao H, Wang D and Cao Z: Bone morphogenetic protein-9 enhances osteogenic differentiation of human periodontal ligament stem cells via the JNK pathway. PLoS One 12: e0169123, 2017.

27. Wada N, Menicanin D, Shi S, Bartold PM and Gronthos S: Immunomodulatory properties of human periodontal ligament stem cells. J Cell Physiol 219: 667-676, 2009.

28. Gronthos S, Mrozik K, Shi S and Bartold PM: Ovine periodontal ligament stem cells: Isolation, characterization, and differentiation potential. Calcif Tissue Int 79: 310-317, 2006.

29. Nagata M, Iwasaki K, Akazawa K, Komaki M, Yokoyama N Izumi Y and Morita I: Conditioned medium from periodontal ligament stem cells enhances periodontal regeneration. Tissue Eng Part A 23: 367-377, 2017.

30. Iwasaki K, Komaki M, Yokoyama N, Tanaka Y, Taki A, Honda I, Kimura Y, Takeda M, Akazawa K, Oda S, et al: Periodontal regeneration using periodontal ligament stem cell-transferred amnion. Tissue Eng Part A 20: 693-704, 2014.

31. Nair PN: Pathogenesis of apical periodontitis and the causes of endodontic failures. Crit Rev Oral Biol Med 15: 348-381, 2004.
32. Kim AR, Ahn KB, Kim HY, Seo HS, Kum KY, Yun CH and Han SH: Streptococcus gordonii lipoproteins induce IL-8 in human periodontal ligament cells. Mol Immunol 91: 218-224, 2017.

33. Wang F, Guan M, Wei L and Yan H: IL18 promotes the secretion of matrix metalloproteinases in human periodontal ligament fibroblasts by activating NF- $\kappa \mathrm{B}$ signaling. Mol Med Rep 19: 703-711, 2019.

34. Bottinger EP, Letterio JJ and Roberts AB: Biology of TGF-beta in knockout and transgenic mouse models. Kidney Int 51: 1355-1360, 1997.

35. Nokhbehsaim M, Winter J, Rath B, Jäger A, Jepsen S and Deschner J: Effects of enamel matrix derivative on periodontal wound healing in an inflammatory environment in vitro. J Clin Periodontol 38: 479-490, 2011.

36. Bosshardt DD, Stadlinger B and Terheyden H: Cell-to-cell communication-periodontal regeneration. Clin Oral Implants Res 26: 229-239, 2015.

37. Rodier F and Campisi J: Four faces of cellular senescence. J Cell Biol 192: 547-556, 2011

38. Coppé JP, Desprez PY, Krtolica A and Campisi J: The senescence-associated secretory phenotype: The dark side of tumor suppression. Annu Rev Pathol 5: 99-118, 2010.

39. Coppé JP, Patil CK, Rodier F, Sun Y, Muñoz DP, Goldstein J, Nelson PS, Desprez PY and Campisi J: Senescence-associated secretory phenotypes reveal cell-nonautonomous functions of oncogenic RAS and the p53 tumor suppressor. PLoS Biol 6: 2853-2868, 2008.

40. Serra MP, Marongiu F, Sini M and Laconi E: Hepatocyte senescence in vivo following preconditioning for liver repopulation. Hepatology 56: 760-768, 2012.

41. Sculean A, Chapple IL and Giannobile WV: Wound models for periodontal and bone regeneration: The role of biologic research. Periodontol 2000 68: 7-20, 2015

42. Li ZY, Liu T, Ma JW, Guo Q, Ma L, Lv QL, Jiang Y, Wei C and Zhang JS: TGF- $\beta$ induces corneal endothelial senescence via increase of mitochondrial reactive oxygen species in chronic corneal allograft failure. Aging (Albany NY) 10: 3474-3485, 2018.

This work is licensed under a Creative Commons Attribution-NonCommercial-NoDerivatives 4.0 International (CC BY-NC-ND 4.0) License. 